\title{
Miller Fisher syndrome: a rare variant of Guillain-Barré syndrome
}

\author{
Luciana Pinto Bandeira ${ }^{a}$, Luize Giuri Palaoroa ${ }^{a}$ Jairo Degenszajn ${ }^{b}$
}

Bandeira LP, Palaoro LG, Degenszajn J. Miller Fisher syndrome: a rare variant of Guillain-Barré syndrome. Autopsy Case Rep [Internet]. 2012;2(3):57-61. http://dx.doi.org/10.4322/acr.2012.027

\section{ABSTRACT}

This report describes the case of a 39-year-old male patient who presented to the emergency room with complaints of impaired balance, diplopia, and nasal voice. The patient had a history of upper respiratory tract infection. The initial physical examination revealed ataxia, ophthalmoplegia, and areflexia, which are consistent with the classic triad of Miller Fisher syndrome, considered a benign variant of Guillain-Barré syndrome. The patient developed peripheral facial paralysis during hospitalization. He underwent a treatment with immunoglobulin for five days, resulting in near complete resolution of the ataxia. However, the ophthalmoplegia and areflexia persisted. He was discharged to outpatient follow-up.

Keywords: Miller Fisher syndrome; Ataxia; Ophthalmoplegia; GQ1b ganglioside [Supplementary concept]; Facial nerve.

\section{CASE REPORT}

A previously healthy 39-year-old male patient of Asian ancestry first presented to the emergency room with a four-day history of dizziness and impaired balance, he felt as if he were "drunk". He was discharged after symptomatic treatment. The patient returned two days later with complaints of diplopia, nasal voice, and persistence of the previous symptoms, and therefore he was admitted for clinical investigation. He reported that two weeks before the onset of those symptoms, he had had "the flu" with rhinorrhea, nasal obstruction, and headache.

Physical examination at admission showed a well-being patient, conscious and alert, afebrile and acyanotic. He had no jaundice, was well hydrated, eupneic, and the blood pressure was normal. The cardiovascular, respiratory, and digestive systems showed no abnormalities on examination. Neurological examination findings were as follows: a Glasgow Coma Scale score of 15; no signs of meningeal irritation; a negative Romberg sign; "drunken sailor" gait; finger-to-nose maneuver with intention tremor, especially on the left side; blepharoptosis, especially on the right; bilateral mydriasis with absence of photomotor and consensual reflexes; paresis of the III, IV and $\mathrm{VI}$ cranial nerves determining incapacity of the horizontal and vertical eye movements as well as arreflexia of the deep reflexes.

The initial laboratory work up showed leukocytosis, on total blood cell count, with no shift to the left; normal electrolyte and renal function

\footnotetext{
a Department of Internal Medicine - Hospital das Clínicas - Faculdade de Medicina - Universidade de São Paulo, São Paulo/SP - Brazil. ${ }^{b}$ Department of Internal Medicine - Hospital Universitário - Universidade de São Paulo, São Paulo/SP - Brazil.

Copyright (c) 2012 Autopsy and Case Reports - This is an Open Access article distributed of terms of the Creative Commons Attribution NonCommercial License (http://creativecommons.org/licenses/by/3.0/) which permits unrestricted non-commercial use, distribution, and reproduction in any médium provided article is properly cited.
} 
determinations. Because the working diagnosis was brainstem encephalitis, CSF was collected for analysis, which showed the following: a clear and colorless fluid with $1 \mathrm{cell} / \mathrm{mm}^{3}, 1$ red blood cell/ $\mathrm{mm}^{3}$, a protein level of $45 \mathrm{mg} / \mathrm{dl}$, a glucose level of $66 \mathrm{mg} / \mathrm{dl}$, and a lactate level of $14 \mathrm{mg} / \mathrm{dl}$. Pandy's reaction was negative, the India ink test was negative, and the adenosine deaminase level was within the normal range. A microbiological analysis showed no bacterial growth.

The findings on non-contrast enhanced computed tomography (CT) and CT angiography of the skull were normal, ruling out the hypothesis of venous sinus thrombosis.

Taking into account the clinical data (anamnesis), together with the neurological findings characterizing the triad of ataxia, ophthalmoplegia, and areflexia following an episode of upper respiratory tract infection, and considering that physical examination and laboratory tests revealed no other abnormalities, the Miller Fisher syndrome was considered as the final diagnosis.

The patient developed peripheral facial paralysis during hospitalization and underwent 5 days of treatment with intravenous human immunoglobulin. The ataxia lessened significantly, as well as the motor coordination improved. In addition, there was complete resolution of the bilateral mydriasis and bilateral recovery of the photomotor reflex. However, the areflexia in upper and lower limbs persisted at hospital discharge, as did the bilateral ophthalmoplegia. The patient tested positive for anti-GQ1b antibodies, resulting in $1 / 6400$ (reference value $<1 / 100$ ). The patient was discharged with the recommendation for specialized outpatient follow-up.

\section{DISCUSSION}

Miller Fisher syndrome is considered a benign variant of Guillain-Barré syndrome, which manifests with the clinical triad of ataxia, areflexia, and ophthalmoplegia. However, in order to diagnose Miller Fisher syndrome, not all signs of the clinical triad need to be present, which can often make the diagnosis difficult. Miller Fisher syndrome is a multifocal neuropathy, classified as an acute, autoimmune, inflammatory demyelinating disease that primarily affects peripheral neurons. The syndrome was first described as affecting the peripheral nervous system, and, in the literature, there remains controversy regarding the involvement of the central nervous system (CNS). ${ }^{1}$

A review published by Berlit in 1992 showed that there have been reports of pathological findings on ancillary tests such as electroencephalography (38 cases), brain CT (8 cases), and magnetic resonance imaging of the brain ( 2 cases), thereby providing possible evidence of involvement of the CNS in Miller Fisher syndrome. ${ }^{1}$

Miller Fisher syndrome is a rare disease. The exact incidence of the syndrome is not known and can vary among geographic areas. In a study conducted in the southwestern region of the Netherlands, the incidence was estimated to be approximately 1-2 cases per million population per year. ${ }^{2}$ Various authors have reported an annual incidence of 0.9 per million population, showing that the disease affects patients between 13 and 78 years of age, being more common among patients in their 40s, and more prevalent in males than in females, at a ratio of $2: 1 .^{3}$ In addition, the incidence of the syndrome appears to be higher among Asians. ${ }^{4}$

The triad of ataxia, areflexia, and ophthalmoplegia as a variant of Guillain-Barré syndrome was first described in 1932 by Collier. ${ }^{1}$ In 1956, Miller Fisher reported three patients with ataxia, areflexia, and ophthalmoplegia as a separate entity. ${ }^{1}$ Since then, 223 cases of Miller Fisher syndrome have been reported. ${ }^{1}$

Studies show that approximately $70 \%$ of cases are preceded (by 10 days, on average) by respiratory or intestinal tract infection ${ }^{1,5-7}$, as in the case described here, in which the patient had upper airway infection two weeks before the onset of symptoms. The infectious agents most commonly involved include Campylobacter jejuni, Haemophilus influenzae, Epstein-Barr virus, and cytomegalovirus. In some patients, however, no association with infection is found..$^{6,8}$

Snyder et al. demonstrated the association between Miller Fisher syndrome and the following infectious agents: Campylobacter jejuni, in $21 \%$; Haemophilus influenzae, in 8\%; cytomegalovirus, in 4\%; and Mycoplasma pneumoniae; in 3\%. Less commonly found agents included EpsteinBarr virus, Coxiella burnetii, Pasteurella multocida, Helicobacter pylori, Aspergillus spp., and varicella 
zoster virus. ${ }^{8}$ Cases of Miller Fisher syndrome after influenza vaccination have also been documented. ${ }^{8}$

Recently, there have been published reports of five cases of variants of Guillain-Barré syndrome that occurred four weeks after H1N1 vaccination during the 2010 and 2011 campaigns. In those cases, there was no evidence of other possible etiologies to explain the clinical course characterized by ataxia, areflexia, dysautonomia, sphincter dysfunction, and protein-cytological dissociation in the CSF. One patient developed the classic Miller Fisher syndrome after H1N1 vaccination. All those patients were treated with immunoglobulin, with variable responses. It was concluded that administration of the vaccine could be associated with the development of variants of Guillain-Barré syndrome, and further studies are required for confirmation. ${ }^{9}$

Infectious agents are believed to contribute to the formation of anti-GQ1b IgG antibodies, which were first credited as determining factors in the pathogenesis of Miller Fisher syndrome by Chiba et al. ${ }^{10,11}$ Studies have shown that, on average, more than $90 \%$ of patients with Miller Fisher syndrome have serum antibodies to the GQ1b and GT1a gangliosides. ${ }^{2,10}$ However, because these antibodies can be found in patients with other variants of Guillain-Barré syndrome, acute ataxia (without ophthalmoplegia), or acute ophthalmoplegia (without ataxia), they are not specific to Miller Fisher syndrome. ${ }^{2,8}$ These antibodies are likely induced by molecular mimicry during the preceding infection and are pathogenic to peripheral nerves. In general, these antibodies disappear within weeks, concomitantly with clinical improvement. ${ }^{7}$ Less commonly, antibodies to other gangliosides, including GT1a, GD3, GD1b, and GT1ba, can also be detected. ${ }^{2}$ These antibodies, less commonly, are also present in the CSF of patients with Miller Fisher syndrome, and, in general, titers of these antibodies are much lower in the CSF than in serum. ${ }^{2}$

Regarding the involvement of the cranial nerves, we should bear in mind that the oculomotor nerve fibers are rich in GQ1b antigen. That might explain the involvement of these fibers in Miller Fisher syndrome and the observed high frequency of ophthalmoplegia with serum positivity to this antigen in patients with Miller Fisher syndrome. ${ }^{12}$

The most common initial symptom is diplopia (in $38.6 \%$ ), followed by gait disorders (in $20.6 \%$ ). Areflexia is present in $81.6 \%$ of cases.
The involvement of cranial nerves other than the oculomotor was reported in 127 cases $^{1}$ : facial nerve (in 45.7\%); glossopharyngeal and vagus nerve (in 39.9\%); and hypoglossal nerve (in 13\%). Other less common signs and symptoms include blepharoptosis, photophobia, dysphagia, and headache. ${ }^{8}$ The pathogenesis of ataxia has yet to be determined and fully understood. Central and peripheral mechanisms might be involved, comprising a proprioceptive and/or cerebellar component. Further studies would be needed to come to a conclusion. Controversies regarding this issue persist in the literature reviewed, because immunohistochemical studies have shown that antiGQ1b antibodies, which are involved in this entity, stain sensory neurons in the dorsal root ganglion and a population of cerebellar neurons. Therefore, it is possible that the two mechanisms are associated. ${ }^{12}$

In addition to the classic triad of ataxia, ophthalmoplegia, and areflexia, the clinical presentation of Miller Fisher syndrome includes the involvement of other cranial nerves, with the facial nerve being the most commonly affected nerve, as observed in this case. Chief among spared cranial nerves is the optic nerve, which is rarely affected. ${ }^{12}$

The diagnosis is based on the clinical presentation, combined with testing of the CSF, which shows characteristic protein-cytological dissociation and high levels of anti-GQ1b $\lg G$ antibodies determined by ELISA. It should be borne in mind that the CSF can be normal, especially in the initial phase of the disease, which does not rule out the diagnosis, as in the case reported here.

In a review of the literature on Miller Fisher syndrome conducted in 1992, Berlit et al. found high protein levels in the CSF of 134 patients (64.4\% of the cases), whereas, in 56 patients, the CSF was normal. ${ }^{1}$ Magnetic resonance imaging of the brain shows no specific lesions. ${ }^{7}$ Common electroneuromyography findings include increased distal latency and action potential abnormalities of the sensory nerves. ${ }^{12}$

Similarly to imaging tests, CSF testing is also performed to exclude other diseases. The differential diagnosis with other CNS pathological processes, such as infectious processes, granulomatous processes, demyelinating diseases, intoxications, and vasculitis, should be considered in the clinical investigation. ${ }^{12}$ 
The treatment of Miller Fisher syndrome is based on support measures and monitoring of vital signs. Rarely, the disease evolves to a stage that requires intensive care or mechanical ventilation, which is more common in Guillain-Barré syndrome. According to the literature, the use of intravenous immunoglobulin or plasmapheresis shows controversial results. In most patients receiving either treatment, recovery is more rapid, when compared with those not receiving any treatment, but this difference is not statistically significant. ${ }^{13-15}$ Complete recovery occurs in $80 \%$ of patients within one to two years. A permanent deficit is seen in $5-10 \%$ of patients, and mortality ranges from 2 to $3 \%$, being caused by secondary infections. ${ }^{7,16-18}$ Recurrence of the syndrome has been reported in seven cases. ${ }^{1}$

\section{REFERENCES}

1. Berlit P, Rakicky J. The Miller Fisher syndrome. Review of the literature. J. Clin Neuroophthalmol. 1992;12(1):57-63. PMid:1532603.

2. Jacobs BA, van Doorn PA. Miller Fisher Syndrome. Netherlands: Interuniversitair Steunput Neuromusculair Onderzoek; 2005 May 10 [cited 2012 Jul 6]. Available from: http://www.isno.nl/Neuromuscular_Info/Disorders_ and_diagnostics/Disorders/Items/Miller_Fisher_Syndrome/ Default.aspx?

3. Santos BPP, Dutra LMA. [Miller Fisher Syndrome - A Case Report]. Com. Ciências Saúde. 2011;22(2):157-62. Portuguese.

4. Shoamanesh A, Chapman K, Traboulsee A. Postvaccination Miller Fisher Syndrome. Arch Neurol. 2011;68(10):1327-9. Pmid:21987549. http://dx.doi.org/10.1001/archneurol.2011.236

5. Paparounas K. Anti-GQ1b ganglioside antibody in peripheral nervous system disorders: pathophysiologic role and clinical relevance. Arch Neurol. 2004;61(7):1013-6. PMid:15262730. http://dx.doi.org/10.1001/archneur.61.7.1013

6. Koga M, Gilbert M, Li J, et al. Antecedent infections in Fisher syndrome: a common pathogenesis of molecular mimicry. Neurology 2005;64(9):1605-11. PMid:15883324. http://dx.doi.org/10.1212/01.WNL.0000160399.08456.7C

7. Damiani D, Laudanna N, Damiani D. Miller Fisher syndrome: diagnosis considerations and differentials diagnosis. Rev Bras Clin Med São Paulo. 2011;9(6):423-7.
8. Snyder LA, Rismondo V, Miller NR. The Fisher variant of Guillain-Barré Syndrome(Fisher syndrome). J. Clin Neuroophthalmol. 2009;29(4):312-20. PMid:19952907. http://dx.doi.org/10.1097/WNO.0b013e3181c2514b

9. Shaikh AG, Termsarasab P, Nwankwo C, Rao-Frisch A, Katirzi B. Atypical forms of Guillain-Barré syndrome and H1N1-influenza vaccination. Vaccine. 2012;30(22):3251-4. PMid:22429755. http://dx.doi.org/10.1016/j. vaccine.2012.03.013

10. Chiba A, Kusunoki S, Shimizu T, Kanazawa I. Serum IgG antibody to ganglioside GQ1b is a possible marker of Miller Fisher syndrome. Ann Neurol. 1992;31(6):677-9. PMid:1514781. http://dx.doi.org/10.1002/ana.410310619

11. Chiba A, Kusunoki S, Obata $H$, Machinami $R$, Kanzawa I. Serum anti-GQ1b IgG antibody is associated with ophthalmoplegia in Miller Fisher syndrome and GuillainBarré syndrome: clinical and immunohistochemical studies. Neurology. 1993;43(10):1911-7. PMid:8413947. http://dx.doi. org/10.1212/WNL.43.10.1911

12. Carvalho AA, Galvão MD, Rocha MS, Piccolo AC, Maia SC. Miller Fisher syndrome and optic neuritis: case report. Arq Neuropsiquiatr. 2000;58(4):1115-7. PMid:11105082. http:// dx.doi.org/10.1590/S0004-282X2000000600021

13. Overell JR, Hsieh ST, Odaka M, Yuki N, Willison HJ. Treatment for Fisher syndrome, Bickerstaff's brainstem encephalitis and related disorders. Cochrane Database Syst Rev. 2007;24(1):CD004761.

14. Mori M, Kuwabara S, Fukutake T, Hattori T. Plasmapheresis and Miller Fisher syndrome: analysis of 50 consecutive cases. J Neurol Neurosurg Psychiatry. 2002;72(5):680. PMid:50411. http://dx.doi.org/10.1136/jnnp.72.5.680

15. Mori M, Kuwabara S, Fukutake T, Hattori T.Intravenous immunoglobulin therapy for Miller Fisher syndrome. Neurology. 2007;68(14):1144-6. PMid:17404197. http:// dx.doi.org/10.1212/01.wnl.0000258673.31824.61

16. Mori M, Kuwabara S, Fukutake T, Yuki N, Hattori T. Clinical features and prognosis of Miller Fisher syndrome. Neurology. 2001;56(8):1104-6. PMid:11320188. http://dx.doi. org/10.1212/WNL.56.8.1104

17. Griffin JW, Li CY, Ho TW, et al. Guillain-Barré syndrome in northern China. The spectrum of neuropathological changes in clinically defined cases. Brain. 1995;118(Pt 3):577-95. PMid:7600080. http://dx.doi.org/10.1093/brain/118.3.577

18. McKhann GM, Cornblath DR, Ho T. Clinical and electrophysiological aspects of acute paralytic disease of children and young adults in northern China. Lancet. 1991;338(8767):5937. http://dx.doi.org/10.1016/01406736(91)90606-P 


\section{Conflict of interest: None}

Submitted on: $27^{\text {th }}$ June 2012

Accept on: $13^{\text {th }}$ August 2012

Correspondence: Luciana Pinto Bandeira

Rua Cássio Martins Villaça, 430 - Pacaembu - São Paulo/SP - Brazil

CEP: 01249-000 - Phone: +55 (11) 98101-0037

E-mail: luciana_pbandeira@hotmail.com 
